\title{
Occupational health and safety in Great Britain 1973
}

\author{
J. M. HARRINGTON \\ TUC Centenary Institute of Occupational Health, London School of Hygiene and Tropical \\ Medicine, London
}

Each year, the state of occupational health and safety in Britain is reviewed in this journal by referring to the annual reports of the various inspectorates concerned with specific industrial or occupational activities. Achieving an overview of these reports is a task apparently not undertaken by any single government department. The chief inspectors report variously to the Departments of Employment, Energy, and the Environment. When the Health and Safety Commission is fully operative, the task of reviewing the national situation may be somewhat easier.

The confused and somewhat disorganized system of legislation on industrial hazards in Britain is a reflection of the history of industrialization, rather than a rational attempt to protect the worker from the risks of his occupation. The legislation proceeding from the Robens Report which received the Royal Assent in 1974 attempts, among other things, to clarify and simplify these complicated legal provisions. The inspectorates of Factories, Offices, Shops and Railway Premises, Alkali, etc., Works, and Mines and Quarries, are now within the same administrative framework and thus co-ordinating their activities rather more than they have in the past.

This major change in industrial health and safety is generally welcomed by allusion in most of the current annual reports, although the Chief Alkali Inspector was 'saddened to think that the independent existence of this fine inspectorate might soon come to an end'. His reasons for such sadness are not detailed but one possibility is the fear that the new Commission may not be as effective as the separate inspectorates were in controlling hazards at work. Another more cynical possibility is sadness at the loss of some executive power. Nevertheless, the Commission has a major problem of co-ordination on its hands at head office before it can get down to dealing with the problems in the field. In addition the annual reports from 1975 onwards will include a description of the hazards of the five million or so workers not previously covered by legislation.

\section{General}

The size of the annual reports bears some correlation with the size of the population they cover, although in the case of the 110th Annual Report on Alkali etc. Works (Department of the Environment, 1974) the population relates to the number of works rather than workers. The type of inspection undertaken is also reflected in the emphasis each chief inspector lays on his main responsibilities. Mr Bryan Harvey, then at the Factory Inspectorate, emphasizes the importance of decreasing the number of accidents and injuries at work, and his Department is actively engaged in an analysis of the causes of accidents. In recent years instead of attempting to inspect as many places of work as possible on a cyclical basis, it concentrates on more detailed studies of large high-risk factories. The implementation of the Offices, Shops and Railway Premises Act, 1963 continues to involve general surveillance of such establishments under local authority responsibility. The Alkali Inspectorate also attempts widespread cover of over $\mathbf{2 0 0 0}$ works registered under the Act to control emissions from the plant, while the Chief Inspector of Mines and Quarries (Department of Energy, 1974a) emphasizes the need to monitor health and safety in the mining communities. The medical aspects of enforcing the law are largely confined to the reports of the Factories (Department of Employment, 1974b), and Mines and Quarries (Department of Energy, 1974a), and it is in these reports that accident and injury analysis achieve their greatest importance.

\section{Specific reports}

Factories

In 1973 reported accidents increased from 258137 to 
272 518. Altogether 549 deaths were reported, 81 more than in 1972. Absolute figures, however, can give a false picture unless they are related to the population at risk. The 1973 figures represented 4.3 accidents per 100000 workers compared with 3.9 in 1972. Serious injury rates fell from 580 per 100000 in 1972, to 550 in 1973. Statistically, therefore, the change is small enough to suggest that the experience of a single year needs to be treated with caution.

Nevertheless the accident and fatality rates for the construction industry continue to cause concern to the Chief Inspector. He states that 'the incidence of accidents in construction is significantly worse than that for any other industry for which I am responsible'. Its problems are not only related to the $22 \cdot 7$ deaths per 100000 workers at risk, but also to the widely dispersed nature of the industry. The size of construction operations varies enormously and the work force is highly mobile and engaged in inherently dangerous work. Training and experience in handling potentially lethal plant is often limited and 'far too many' of the employers are apathetic about safety in the industry.

As a consequence, the Factory Inspectorate is to set up a special unit at headquarters to monitor and investigate the safety record of the high-risk companies. The major risk areas seems to be falsework (the collapse of such temporary constructions was the underlying cause of the Loddon Bridge accident in October 1972), mobile cranes, scaffolding, excavations, and diving operations.

Of the fatalities in the construction industry $10 \%$ were due to excavation accidents. Despite this, the inspectorate is still having difficulties in convincing some construction site managers that the walls of such excavations need to be shored up to prevent falls of earth on to the men working below.

Diving and underwater working increased in 1973, particularly in connexion with oil and gas drilling in the North Sea. Safety standards in the diving industry are often inadequate, particularly in work undertaken by the large number of independent small units.

In the report it is emphasized that major disasters such as the explosions at Sheffield and Flixborough often involve large numbers of workers and the inspectorate feels that the problems of tackling senior management are greater with the multinational companies than the small operators.

Attitudes of mind need to be changed rather than the physical aspects of safety and the inspectorate believes that absenteeism, of which accident injuries form a considerable part, may be a function of poor management. The Accident Prevention Advisory Unit is actively engaged in trying to educate management as well as studying the pathogenesis of accidents in industry. In-depth analysis of a random sample of accidents reveals that in the construction industry 'no reasonably practicable precautions were available' in nearly $50 \%$. A further $28 \%$ involved breach of regulations, and of the remainder, management were solely responsible for the lack of precautions in over half the accidents.

Mr Harvey likens the Factory Inspectorate to a watchdog. It has to have a good nose to sniff out problems, a loud bark for dealing with recalcitrant management or workers, and teeth to be used effectively if infrequently. The teeth were used on 1800 occasions in 1973, compared with 1200 in 1970, and 3725 convictions were achieved.

The occupational hygiene laboratories moved to new enlarged premises in 1973 and now must rank as one of the best equipped in the country. In that year they analysed 9282 poisons and 3568 fibrogenic dusts; the comparable figures for 1966 were 1333 and 571. In addition to being capable of analysing a wide range of toxic materials, the laboratory has demonstrated its ability to deal with large numbers of specimens of a single substance, for example 3739 analyses for lead and 2002 for asbestos.

\section{Offices, shops, and railway premises}

In comparison with the risks of working in a factory, the hazards of shops and offices seem small, but nevertheless the environmental conditions are often inadequate. One of the major problems confronting the three quarters of a million premises employing eight million people is defective ventilation, particularly with excessively high temperatures. This used to be a problem restricted to antiquated poorly ventilated buildings but the report (Department of Employment, 1974a), perhaps surprisingly, notes that it is the modern offices which now produce the greatest problems largely because of solar gain from vast expanses of glass.

Although the minimum acceptable temperature in offices is $16^{\circ} \mathrm{C}$, few complaints are received about low temperatures, though draughts are a major source of discomfort to supermarket check-out girls and people working in reception areas.

Accident rates are about $8 \%$ of those for factories, and fatality rates have fallen to 0.2 per 100000 employees at risk. Fatalities and serious injuries, unambiguously the direct result of an accident at work, are classified as Group 1 injuries and the rates vary greatly with the type of premises.

Falls of persons were responsible for $45 \%$ of all fatalities and $35 \%$ of all accidents. This is reflected in the types of injury where half were due to fractures, dislocations, and crushings.

One of the perennial problems of enforcing the Offices, Shops and Railway Premises Act is making employers aware that they have certain standards to maintain. Offices at mines, quarries, and factories 


\begin{tabular}{|c|c|c|c|c|c|}
\hline Group 1 & Offices & Retail shops & $\begin{array}{l}\text { Wholesale } \\
\text { departments } \\
\text { warehouses }\end{array}$ & Canteens & Overall rate \\
\hline $\begin{array}{l}\text { Injury rate (per } \\
100000 \text { employees) }\end{array}$ & 25 & 65 & 150 & 110 & 45 \\
\hline
\end{tabular}

are usually no problem because management and staff are aware of legislation governing the health of workers. Nevertheless the smaller shops and offices are often totally ignorant of the law regarding their employees and local authorities may have an easier task in educating such people when the new Health and Safety Act is fully operative.

\section{Mines and quarries}

Three major disasters overshadow this report (Department of Energy, 1974a). The Lofthouse Colliery disaster was due to an inrush of water which killed seven men; at Seafield, five died as a result of a roof fall; and an overwind accident at Markham killed 18 men. These accidents helped to raise the fatalities to 80 compared with 64 in 1972 and the injuries rose to 553 (519 in 1972). The death rates, however, remain about the same at 0.15 per 100000 man shifts and the accident rate increased from $1 \cdot 10$ to 1.14 per 100000 man shifts.

The three disasters have led to the Statement of Intent jointly issued by the National Coal Board, the mining unions and the professional bodies concerned, to undertake a complete review of all safety arrangements in the industry.

Falls of ground, despite the Seafield incident, have decreased but the report points out that 'far too many' persons were injured in the prop-free front area which should also be a 'man free' area. Similar downward trends have continued in the deaths and injuries from haulage and transport accidents which are now the lowest ever recorded.

Increased mechanization below ground has led, perhaps inevitably, to an increase in accidents attributed to machinery and they now account for $10 \%$ of all underground accidents. There were 17 explosions caused by frictional sparking, by cutting, or power loading machines out of a total of 20 explosions due to all causes, but happily no injuries were reported.

There were 51 fires underground, a $47 \%$ increase on 1972 figures. Half of these were due to mechanical friction on belt conveyors. The Safety in Mines Research Establishment is actively engaged in work on the mechanism of gas ignition and of ways to prevent it.

Pneumoconiosis is mentioned in the Mines and Quarries Report, but a more detailed account of the 1972 figures appears in the Digest of Pneumoconiosis Statistics (Department of Energy, 1974c). The coal mining industry accounts for $65 \%$ of the new cases each year. In 1972 this meant 626 new cases among coal miners or 2.3 cases per 1000 employed. In 1973 the total had dropped to 515 or 2.0 cases per 1000 and the progression index had fallen from $11 \cdot 3$ in 1972 , to 8.0 in 1973 . Increased mechanization had been held responsible for the rise in the progression index over the period 1969-72, but the improved 1973 figures may be partly a reflection of the rise in approved long wall faces from 90.5 to $93.5 \%$.

The Digest of Pneumoconiosis Statistics for 1972 also contains details of the other 293 cases of pneumoconiosis first diagnosed in that year and unrelated to coal mining. One hundred and twentyfive $(42.7 \%)$ were due to asbestos, $31(10.6 \%)$ to iron foundry work, and $28(9 \cdot 6 \%)$ to slate mining and quarrying.

Quarrying in 1973 resulted in 14 deaths and 88 injuries compared with 15 deaths and 98 injuries in the previous year. Accident rates have oscillated about a mean of 0.45 per 100000 manshifts for the past six years, which is 2.5 times lower than in coal mining. The fatality rate is still four times that of the coal industry, so much remains to be done to improve these figures.

\section{Alkali \&c. works}

This report (Department of the Environment, 1974) covers 2158 works involving 3197 registered processes. The Inspectorate carried out 13680 inspections, but little is said in the report about the human aspects of air pollution. The Chief Inspector has attempted this year to give a detailed account of his Inspectorate's definition of 'best practicable means', a phrase often misinterpreted by critics of their methods. The lengthy exposition defends 'bpm', as the alkali people often call it, as the most effective way of controlling emissions taking cost and improved technology into account. It gives flexibility to the alkali inspector's advice. The rest of the report is an account of work carried out in plants emitting different fumes and dust, and demonstrates the cooperation involved between the Inspectorate, local authorities, and industry. The Inspectorate still seems concerned about divulging information they obtain to the lay public, but the recently convened Working Party of the Clean Air Council hopes to solve some of these problems, probably by issuing expert interpretation of the information at the time of its publication. 


\section{Health and social security}

The Annual Report for 1973 (Department of Health and Social Security, 1974) contains little of relevance to health and safety at work. It is largely concerned with the reorganization of the National Health Service. The expenditure on health and personal social services exceeded $£ 2600$ million of which $50 \%$ was spent on hospitals. National Health Service contributions paid for $7.5 \%$ of the total cost. The report did not comment on the health of the three quarters of a million employees in the health service.

\section{Conclusions}

The conclusions reached after perusing these reports concern their variation in size, quality, and relevance rather than their content. Statistically, greater uniformity must be achieved within individual reports and particularly between reports so that valid comparisons can be readilymade. The Chief Inspector of Factories Annual Report (Department of Employment, 1974b) is essential reading for all who have taken the trouble to read this article and it is clearly the best of the reports in terms of clarity of exposition and standard of statistical analysis. Even here, however, confusion arises as denominators are changed from table to table, leaving the reader rather con- fused. The overall impression is that the reports are valuable sources of information on health and safety at work, but much effort is required of the reader to extract the relevant information.

\section{References}

Department of Employment (1974a). Annual Report of the Offices, Shops and Railway Premises Act for 1973. HMSO, London.

(1974b). HM Chief Inspector of Factories Annual Report 1973. Cmnd 5708. HMSO, London.

Department of Energy (1974a). Report of the HM Chief Inspector of Mines and Quarries for 1973. HMSO, London.

_ - (1974b). 52nd Annual Report of the Safety in Mines Research Establishment for 1973. HMSO, London.

- (1974c). Digest of Pneumoconiosis Statistics for 1972. HMSO, London.

Department of the Environment (1974). 110th Annual Report on Alkali \&c. Works 1973. HMSO, London.

Department of Health and Social Security (1974). Annual Report for 1973. Cmnd 5700. HMSO, London.

Received for publication 5 February 1975.

Accepted for publication 25 February 1975. 